\title{
Effect of Plastic Deformation on Compliance Curve Based Crack Closure Measurement
}

\author{
M.A. Mohin ${ }^{1, a}$, Y.G. $\mathrm{Xu}^{2, \mathrm{~b}^{*}}$, A. Lewis ${ }^{1, \mathrm{c}}$, and A. Chrysanthou ${ }^{1, d}$ \\ ${ }^{1}$ School of Engineering and Technology, University of Hertfordshire, AL10 9AB, UK \\ ${ }^{2}$ School of Aerospace, Transport and Manufacturing, Cranfield University, MK43 OAL, UK \\ am.mohin@herts.ac.uk, byigeng.xu@cranfield.ac.uk ("corresponding author), ca.lewis@herts.ac.uk, \\ da.chrysanthou@herts.ac.uk
}

Keywords: crack closure, compliance curve, damage tolerance design

\begin{abstract}
Fatigue crack growth depends heavily on near tip stress-strain behavior controlled by many micromechanical and microstructural factors. Crack closure is widely used to rationalize crack growth behaviour under complex loading conditions. Reliable crack closure measurement is essential for enhanced damage tolerance design and remains a challenge to the industry. This paper focuses on the effect of plastic deformation ahead of a notch/crack on the non-linearity of compliance curves of 6082-T651 aluminium alloy specimens to highlight a potential issue in the conventional compliance curve based crack closure measurement technique. Experimental and numerical simulation results demonstrate that plastic deformation ahead of the notch will introduce non-linear stress-strain behavior in the absence of crack closure. It is proposed that the effect of crack tip plasticity on the non-linearity of the compliance curve be separated to obtain reliable crack closure measurement.
\end{abstract}

\section{Introduction}

It is generally accepted that crack growth driving force can be influenced by both intrinsic and extrinsic factors occurring around the crack tip. Intrinsic factors include deformation heterogeneity, crack tip plasticity in relation to grain size, secondary phase particle desperation and/or dislocation cell size. Extrinsic factor depends on crack tip shielding processes (e.g. crack closure) which may or may not depend on the microstructure [1]. Fatigue crack closure is the phenomenon which is widely considered to cause reduction in the fatigue crack growth driving force due to the premature contact of crack faces at positive load levels during cyclic loading. The concept of crack closure has been successfully used to rationalize various crack growth behaviours such as overload retardation, underload acceleration, and load sequence effect under variable amplitude loading [2-5]. It is evident that separation of the intrinsic and extrinsic behaviour in terms of isolating the crack closure effect from the crack tip plasticity effect can optimise the crack growth life prediction model. The challenge lies in the reliable measurement of crack closure as the closure process is continuous and dependent on many factors. Fig.1 illustrates a widely used method for crack closure measurement where the crack closure point is identified as the transition point of the linear part (solid line) representing a fully open crack and the non-linear part (dotted line) representing a gradually closed crack. It is however worth noting that reliable identification of the real crack closure point is challenging due to the complex process of crack closure. The non-linearity of the compliance curve can be attributed to other factors in addition to the crack closure. It is therefore not surprising that noticeable discrepancies in the results obtained using this method were reported [6-7]. This paper focuses on the effect of crack-tip plasticity on the non-linearity of compliance curves of 6082-T651 aluminium alloy specimens through experimental and numerical simulation studies. A potential 
issue in the conventional compliance curve based crack closure measurement technique has been highlighted to improve future crack closure measurement.

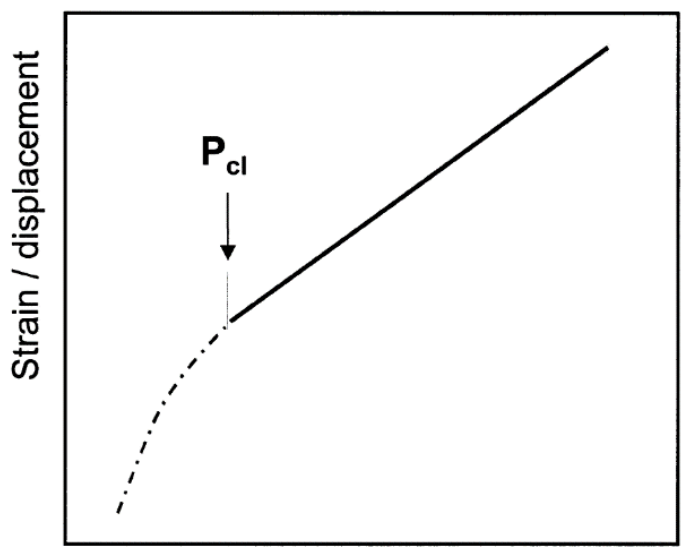

Load, $\mathrm{P}(\mathrm{kN})$

Fig.1 Schematic illustration of compliance curve based crack closure measurement.

Materials, Test Set-up, and Finite Element Mesh

Table 1 shows the chemical compositions of the aluminium alloy (6082A-T651) used for this study. Table 2 shows the mechanical properties of the alloy.

\begin{tabular}{|c|c|c|c|c|c|c|c|c|c|}
\hline Alloy & $\mathrm{Al}$ & $\mathrm{Si}$ & $\mathrm{Fe}$ & $\mathrm{Cu}$ & $\mathrm{Mn}$ & $\mathrm{Cr}$ & $\mathrm{Mg}$ & $\mathrm{Zn}$ & $\mathrm{Ti}$ \\
\hline 6082A- & $\mathrm{Bal}$ & $0.7-1.3$ & 0.50 & 0.10 & $0.40-$ & 0.25 & $0.06-$ & 0.20 & 0.10 \\
T651 & & & $\mathrm{max}$ & $\mathrm{max}$ & 1.00 & $\mathrm{max}$ & 0.120 & $\max$ & $\max$ \\
\hline
\end{tabular}

Table 1 Chemical compositions of Al 6082A-T651.

\begin{tabular}{|c|c|c|c|c|}
\hline Alloy & $\begin{array}{c}\text { Young's modulus } \\
(\mathrm{GPa})\end{array}$ & $\begin{array}{c}\text { Tensile strength } \\
(\mathrm{MPa})\end{array}$ & $\begin{array}{c}\text { Yield strength } \\
(\mathrm{MPa})\end{array}$ & Elongation (\%) \\
\hline 6082A-T651 & 70 & 295 & 255 & 8 \\
\hline
\end{tabular}

Table 2 Mechanical properties of Al 6082A-T651.

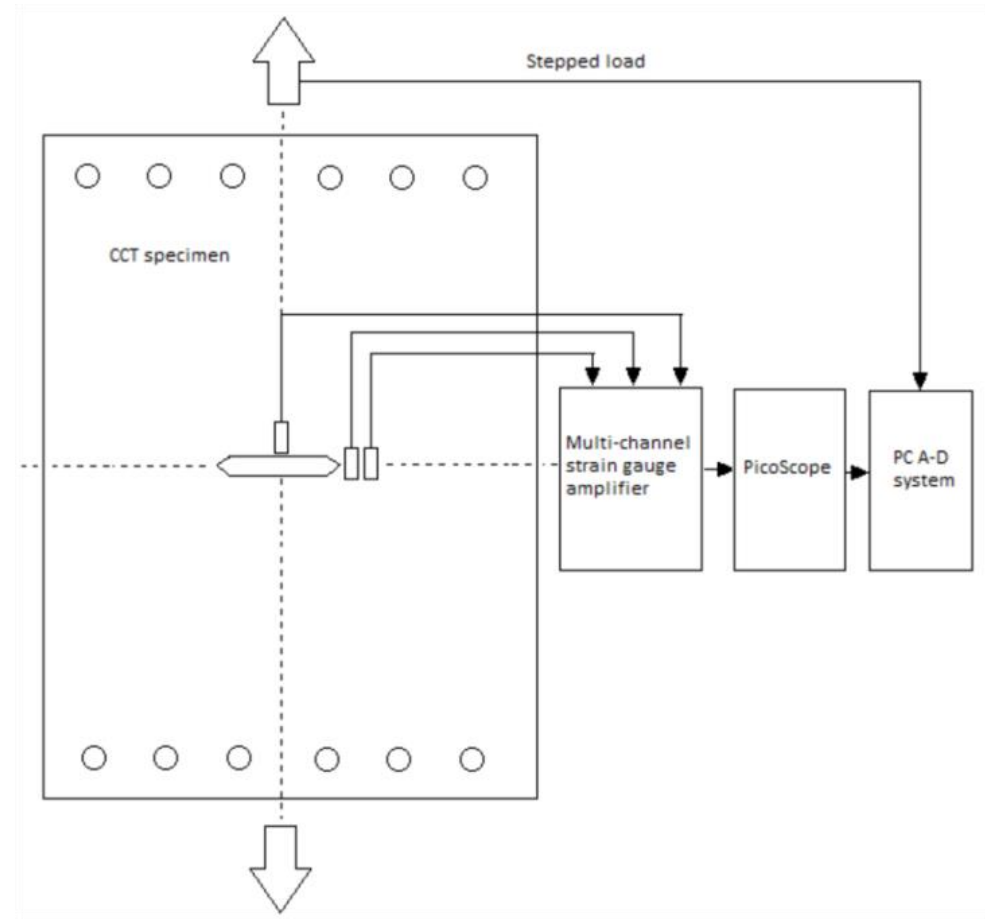

(a)

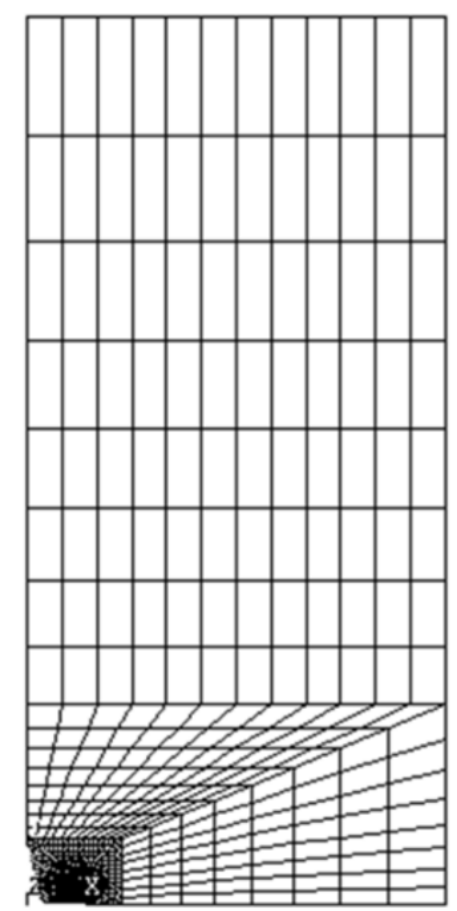

(b)

Fig.2 (a) Schematic view of the test set-up, (b) Mesh of the FE model of the quarter specimen.

Fig.2(a) shows the test set-up. Specimens of $150 \mathrm{~mm}$ width, $400 \mathrm{~mm}$ gauge length and $1.6 \mathrm{~mm}$ 
thickness were loaded slowly from 0 to $26 \mathrm{kN}$ to obtain the compliance curve for a central slot with sharp notches at its ends. Three strain gauges were used to obtain the compliance curves with gauge G1 located 2mm ahead of the notch, G2 located $8 \mathrm{~mm}$ ahead of the notch, and G3 located right in the middle and above the slot. No fatigue loading was applied to the specimen to ensure that no plastic deformation was left behind the notch. As such, the compliance curve obtained from the three strain gauges shouldn't have the effect of crack closure. Fig.2(b) shows the mesh of the quarter specimen where a dense mesh was used near the notch and coarse mesh is used away from the notch. Mesh density study was carried out and the element size around the notch was selected as $24 \mu \mathrm{m}$ which fulfils the criterion of less than one-tenth of the plastic zone size at the notch as recommended in literature [8-9].

\section{Results and Discussion}

Out of the three strain gauges, G1 is the closest one to the notch and chosen to demonstrate the effect of near tip plasticity on compliance curve. Fig.3(a) shows the compliance curve obtained from strain gauge $\mathrm{G} 1$ when the specimen is loaded step-by-step from 0 to $26 \mathrm{kN}$. The compliance curve looks straight and is difficult to detect whether there is any non-linearity. The compliance curve in Fig.3(a) is further processed using an offset technique to identify possible transition point [10]. A linear fit was applied to the data of the upper part of the curve. Fig.3(b) shows the offset compliance curve replotted after the original compliance curve data are offset from the straight line from the linear fit. A clear transition point is shown in Fig.3(b) after the potential non-linearity has been amplified using the offset technique, demonstrating the existence of the non-linearity of the compliance curve. The 'transition point' is found at around $6 k N$ which could be identified as the closure load using the conventional compliance curve based crack closure measurement method.
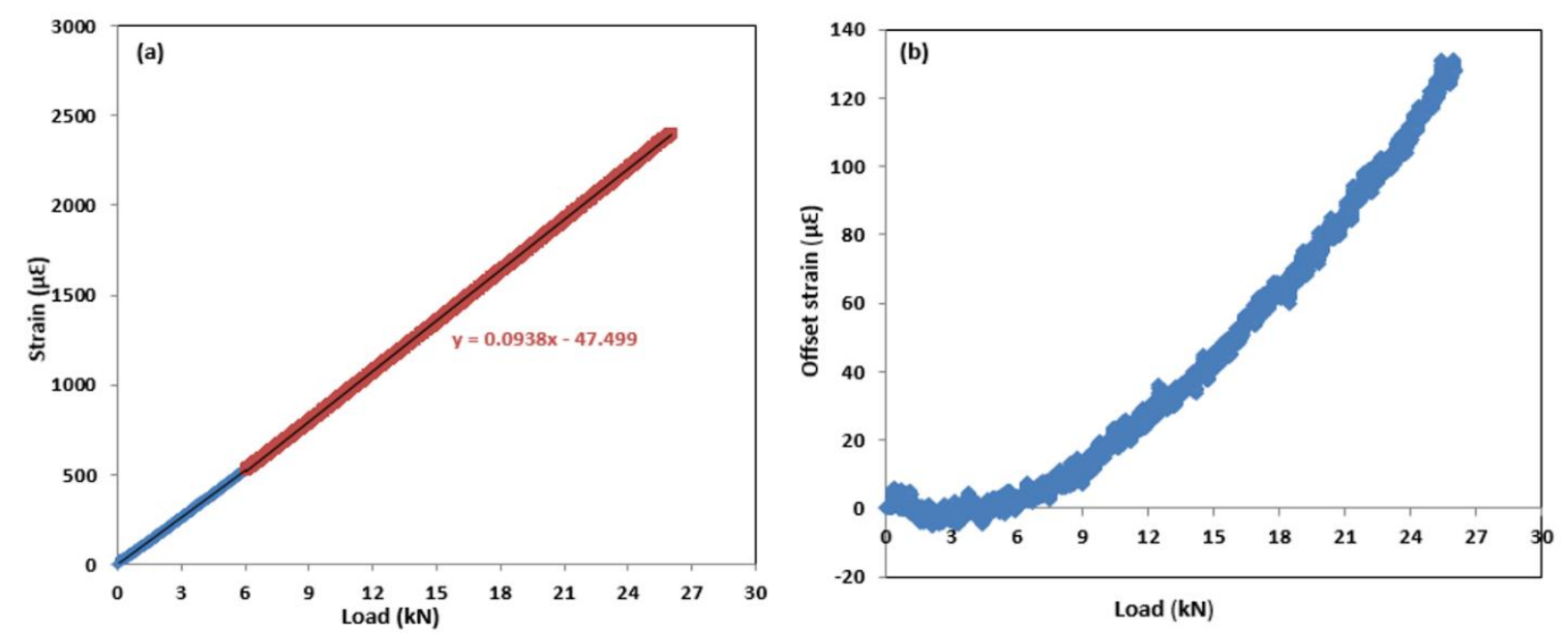

Fig.3 (a) compliance curve from G1 ( $2 \mathrm{~mm}$ ahead of the notch), (b) offset compliance curve from G1.

Fig.4 shows the finite element simulation results of the compliance curve obtained from a node $2 \mathrm{~mm}$ ahead of the notch when the specimen was loaded from $0 \mathrm{kN}$ to $19.2 \mathrm{kN}$. Similar to the experimental results from the strain gauge, Fig.4(a) is the original compliance curve difficult to detect the transition point. Fig.4(b) is the offset compliance curve processed in the same way as for Fig.3(b). A transition point can be seen clearly at around $6 \mathrm{kN}$ in Fig.4(b), which is consistent with the experimental result in Fig.3(b). Similar observations have been made for other strain gauges and nodal positions. The results closer to the notch, however, show stronger non-linearity of the compliance curve. 
It is clear non-linearity exists on the compliance curves obtained through strain gauge measurement and finite element simulation. It is however worth noting that no plastic deformation has been left behind the notch in the current study. As such, the non-linearity is not related to the plasticityinduced crack closure. It is directly linked to the plastic deformation ahead of the notch or crack tip for a fatigue crack. The conventional compliance based crack closure measurement method could therefore identify a false crack closure, causing problems in crack growth life prediction.
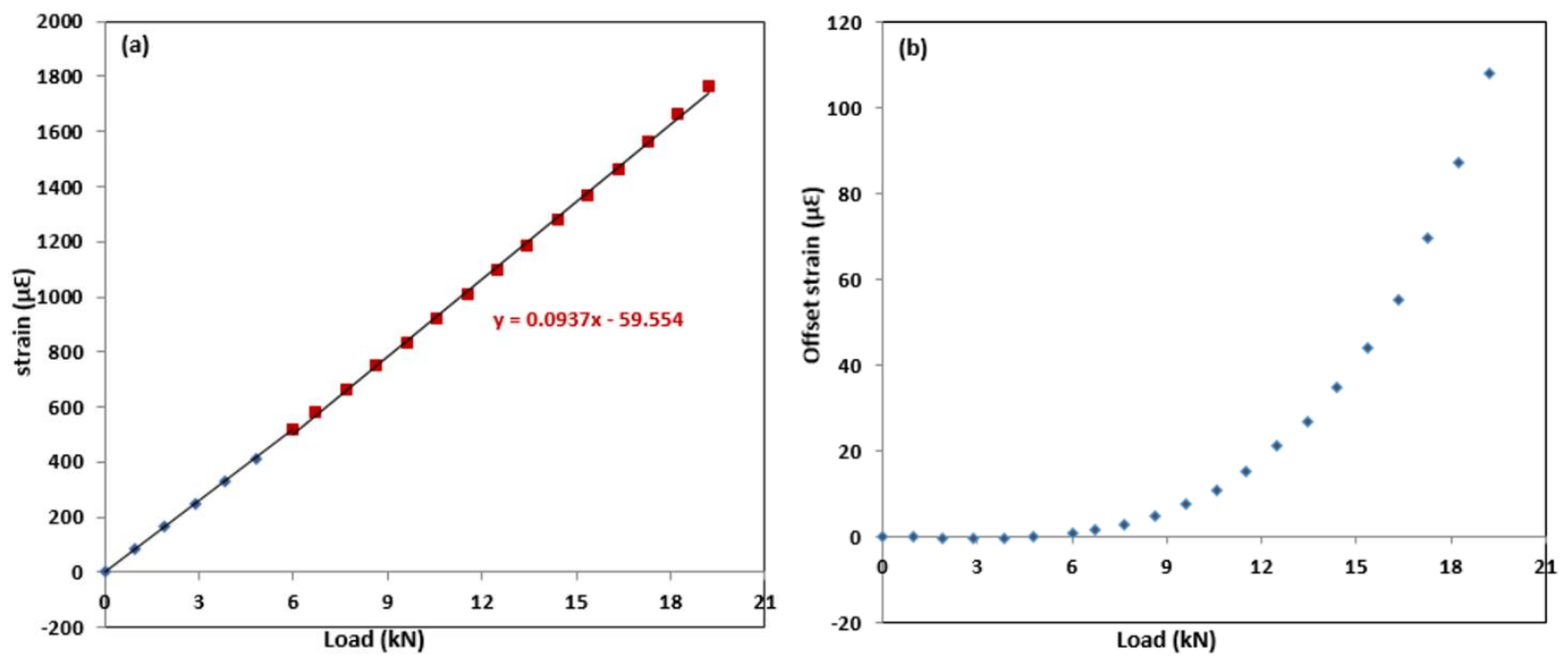

Fig.4 (a) compliance curve from the node $2 \mathrm{~mm}$ ahead of the notch, (b) offset compliance curve from the node $2 \mathrm{~mm}$ ahead of the notch.

\section{Conclusions}

Both the experimental and finite element simulation results demonstrate that the plastic deformation ahead of the notch will introduce non-linearity of the compliance curve, which may lead to the identification of a false crack closure when the popular conventional compliance curve based crack closure measurement method is used. The effect of crack tip plasticity on the non-linearity of the compliance curve should be separated from that of crack closure to obtain reliable crack closure measurement.

\section{References}

[1] $\mathrm{Xu}, \mathrm{Y}$., et al. (2005), Improved fatigue and damage tolerant material design for aerospace industry, Journal of Materials Science and Technology, vol.21, p.856-62.

[2] Toribio, J. and V. Kharin (2011), Plasticity-induced crack closure: A contribution to the debate, European Journal of Mechanics - A/Solids, vol.30, p.105-12.

[3] McEvily, A. and S. Ishihara (2002), On the development of crack closure at high R levels after an overload, Fatigue \& Fracture of Engng Mater \& Struct, vol.25, p.993-8.

[4] Newman Jr, J.C., E.L. Anagnostou, and D. Rusk (2014), Fatigue and crack-growth analyses on 7075-T651 aluminum alloy coupons under constant- and variable-amplitude loading, International Journal of Fatigue, vol.62, p.133-43.

[5] Antunes, F.V., et al. (2015), A numerical study of plasticity induced crack closure under plane strain conditions, International Journal of Fatigue, vol.71, p.75-86.

[6] Phillips, E. (1989), Results of the round robin on opening-load measurement, NASA Technical Memorandum, 101601.

[7] Phillips, E. (1993), Results of the second round robin on opening-load measurement, NASA Technical Memorandum, 109032.

[8] Xu, Y., et al. (2012), Load sequence effect on fatigue damage, Key Engineering Materials, vol.488, p.545-8.

[9] Solanki, K., S. Daniewicz, and J. Newman Jr (2004), Finite element analysis of plasticityinduced fatigue crack closure: an overview, Eng Fracture Mechanics, vol.71, p.149-71. 
[10] Xu, Y., P. Gregson, and I. Sinclair (2000), Systematic assessment and validation of compliance-based crack closure measurements in fatigue, Materials Science and Engineering: A, vol.284, p.114-25. 
2016-09-30

\section{Effect of plastic deformation on} compliance curve based crack closure measureme

Mohin, M.

Trans Tech Publications

M.A. Mohin, Y.G. Xu, A. Lewis, A. Chrysanthou, Effect of plastic deformation on compliance

curve based crack closure measurement, Key Engineering Materials, Vol. 713, pp.240 - 243, 2016

http://dx.doi.org/10.4028/www.scientific.net/KEM.713.240

Downloaded from Cranfield Library Services E-Repository 